\title{
In-hospital clinical outcomes after upper gastrointestinal surgery: Data from an international observational study
}

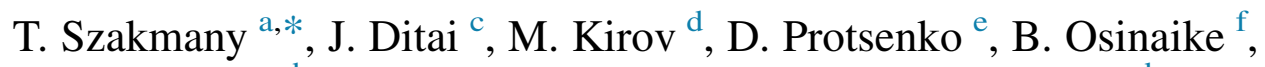 \\ A. Venara ${ }^{\mathrm{h}}, \mathrm{N}$. Demartines ${ }^{\mathrm{g}}$, M. Hubner ${ }^{\mathrm{g}}$, R.M. Pearse ${ }^{\mathrm{b}}$, \\ J.R. Prowle ${ }^{\mathrm{b}}$, \\ on behalf the International Surgical Outcomes Study (ISOS) group ${ }^{1}$

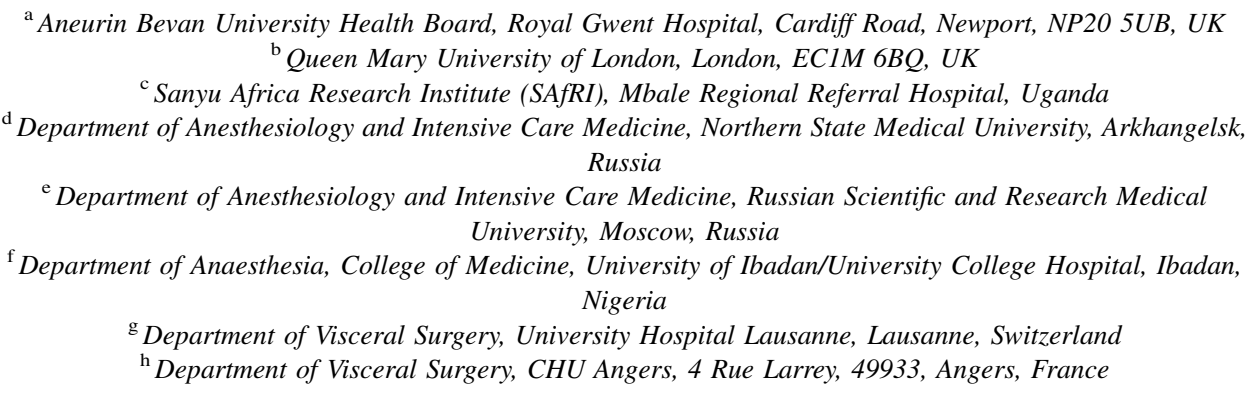

Accepted 4 August 2017

Available online 18 August 2017

\begin{abstract}
Aims: Previous research suggests that patients undergoing upper gastrointestinal surgery are at high risk of poor postoperative outcomes. The aim of our study was to describe patient outcomes after elective upper gastrointestinal surgery at a global level.

Methods: Prospective analysis of data collected during an international seven-day cohort study of 474 hospitals in 27 countries. Patients undergoing elective upper gastrointestinal surgery were recruited. Outcome measures were in-hospital complications and mortality at 30-days. Results are presented as $\mathrm{n}(\%)$ and odds ratios with $95 \%$ confidence intervals.

Results: 2139 patients were included, of whom 498 (23.2\%) developed one or more postoperative complications, with 30 deaths (1.4\%). Patients with complications had longer median hospital stay $11(6-18)$ days vs. $5(2-10)$ days. Infectious complications were most frequent, affecting $368(17.2 \%)$ patients. 328 (15.3\%) patients were admitted to critical care postoperatively, of whom 161 (49.1\%) developed a complication with 14 deaths (4.3\%). In a multivariable logistic regression model we identified age (OR 1.02 [1.01-1.03]), American Society of Anesthesiologists physical status III (OR 2.12 [1.44-3.16]) and IV (OR 3.23 [1.72-6.09]), surgery for cancer (OR 1.63 [1.27-2.11]), open procedure (OR 1.40 [1.10-1.78]), intermediate surgery (OR 1.75 [1.12-2.81]) and major surgery (OR 2.65 [1.72-4.23]) as independent risk factors for postoperative complications. Patients undergoing major surgery for upper gastrointestinal cancer experienced twice the rate of complications compared to those undergoing other procedures (224/578 patients [38.8\%] versus $274 / 1561$ patients [17.6\%]).

Conclusions: Complications and death are common after upper gastrointestinal surgery. Patients undergoing major surgery for cancer are at greatest risk.
\end{abstract}

(C) 2017 Elsevier Ltd, BASO The Association for Cancer Surgery, and the European Society of Surgical Oncology. All rights reserved.

\footnotetext{
* Corresponding author. Critical Care Directorate Royal Gwent Hospital Cardiff Road Newport NP20 2UB United Kingdom.

E-mail address: szakmanyt1@cardiff.ac.uk (T. Szakmany).

${ }^{1}$ Members of study group listed in the Supplementary Appendix.
} 


\section{Introduction}

Currently, 310 million patients undergo surgery worldwide each year, with more procedures taking place in high-income countries [1,2]. Estimates of mortality following in-patient surgery vary from 1 to $4 \%$ [3-10], but it is now recognised that selected high-risk patient groups are more likely to develop life threatening complications. Postoperative complications increase treatment costs $[11,12]$, and reduce both life expectancy and quality of life at a societal level $[13,14]$. Whilst technical errors are unusual during surgery and anaesthesia, poor patient outcomes persist for a variety of reasons. Improvements in the quality of perioperative care for high-risk patients may therefore lead to better patient outcomes.

Patients undergoing surgery to treat cancer of the upper gastrointestinal tract are an important high-risk group. This includes cancers of the oesophagus, and stomach, which have a poor long-term prognosis. Worldwide, oesophageal cancer is the sixth leading cause of death from cancer [15]. Surgical resection remains the only potentially curative treatment, and is integrated in a multimodal therapy, particularly for advanced disease. Recent data from the United Kingdom suggest one third of patients undergoing oesophageal and gastric surgery for cancer, experience postoperative complications, with hospital mortality rates in the region of $3 \%$ [16]. Other reports describe complication rates between 40 and $80 \%$, depending on age, gender, type of surgery, and the presence of chronic disease $[17,18]$.

The need remains to better understand patient outcomes following upper gastrointestinal surgery, to ensure the planning of effective perioperative care, including appropriate patient selection, surgical approach and postoperative provision of critical care [14]. The International Surgical Outcomes Study (ISOS) was recently conducted to evaluate the incidence and risk factors for complications and death after in-patient elective surgery at a global level, and to describe current standards of postoperative care [19]. ISOS included a prospective sub-group analysis to describe in detail, the clinical outcomes and standards of perioperative care following upper gastrointestinal surgery at a global level, and to describe factors associated with complications during the hospital stay and death in this population.

\section{Patients and methods}

\section{Project organisation}

ISOS was approved by the Yorkshire \& Humber Research Ethics Committee (Reference: 13/YH/0371). We then conducted a sub-group analysis of data collected during this international seven-day cohort study of outcomes following elective adult in-patient surgery. Regulatory requirements differed between countries with some requiring research ethics approval and some requiring only data governance approval. Each participating country selected a single data collection week between April and August 2014. Patient data included only that recorded as part of routine care. Local investigators were supported by national co-ordinators, the international study management group, and via a website which provided all study documentation and guidance on study procedures (www.isos.org.uk/ documents). The main ISOS project was registered prospectively with an international trial registry (ISRCTN51817007). The manuscript has been prepared according to the STROBE statement [20].

The inclusion criteria were all adult patients (age $\geq 18$ years) undergoing elective surgery with a planned overnight stay in hospital. Patients undergoing emergency surgery, day-case surgery or radiological procedures were excluded. We aimed to recruit as many hospitals and countries as possible and asked investigators in those hospitals to enrol all eligible patients. No formal sample size calculation was performed. Only hospitals returning valid data describing $\geq 20$ patients and countries with $\geq 10$ participating hospitals were included in the primary analysis of the ISOS dataset [19]. In this sub-group analysis, we included all patients who underwent upper gastrointestinal surgery by the thoracic or abdominal route, using either an open or laparoscopic technique, identified via the eCRF [19]. We also investigated whether there were any differences in outcomes between high-income countries, and low or middle-income countries.

\section{Data collection}

Data describing consecutive patients were collected until hospital discharge on paper case record forms. Data were censored at 30 days following surgery for patients who remained in hospital. Data were anonymised before entry onto a secure internet-based electronic case record form designed specifically for ISOS, which incorporated automated checks for plausibility, consistency and completeness.

\section{Outcome measures}

The primary outcome measure was in-hospital postoperative complications assessed using predefined criteria and graded according to the Clavien-Dindo classification $[21,22]$. The secondary outcome measure was in-hospital mortality. Process measures were admission directly to critical care after surgery, admission to critical care for treatment of a postoperative complication, and duration of hospital stay. A single prospective definition of critical care was used for all countries (a facility routinely capable of admitting patients who require invasive ventilation overnight).

\section{Statistical analysis}

Statistical analysis was performed using SPSS (version 20.0) and R: A language and environment for statistical 
computing ( $\mathrm{R}$ Foundation for Statistical Computing, Vienna, Austria). Categorical variables are presented as number (\%) and continuous variables as mean (SD) where normally distributed and median (IQR) where not normally distributed. Univariable analysis was used to select risk factors for postoperative complications. Multivariable logistic regression analysis was used to develop a generic model in which all previously determined risk factors were entered. The threshold for inclusion of variables in the multivariable analysis was $\mathrm{p}<0.05$. All predictors were entered into the model using forced simultaneous entry. With the expected sample size, a limited number of factors could be included in the model without over fitting, and these were selected based on clinical suitability and assessment of correlated variables. Bootstrapping was used to assess the reliability of the models. Goodness-of-fit tests were performed using the Hosmer-Lemeshow test. A process of forward and backward selection, based on minimisation of Akaike's Information Criterion (AIC), was used to derive the final model [23]. Results are presented as odds ratios with $95 \%$ confidence intervals. For variables included in our final model, univariable logistic regression was then performed to generate unadjusted odd ratios for comparison with the multivariable model. In the main ISOS database, data describing baseline risk factors were missing for a very small proportion of patients [451/44 $814(1 \%)]$. Due to the low proportion of missing data, we performed a complete case analysis where patients with missing data were excluded from the analysis [19].

\section{Results}

Data describing 44814 patients were collected in 474 hospitals in the following countries and regions: Australia, Austria, Belgium, Brazil, Canada, China, Denmark, France, Germany, Greece, Hong Kong, Indonesia, Italy, Malaysia, Netherlands, New Zealand, Nigeria, Portugal, Romania, Russia, South Africa, Spain, Sweden, Switzerland, Uganda, United Kingdom, and the United States of America. Fewer than ten hospitals participated in India, Iraq and Mexico and in accordance with the prospective statistical analysis plan, patients recruited in these countries were excluded from the primary analysis. 2139 patients who underwent upper gastro-intestinal surgery in 369 centres were identified in the ISOS database (4 [2-7] patients per centre; Fig. 1). Baseline patient data are presented in Table 1.

\section{Process measures}

The median stay in a post-anaesthetic care unit was 2 (1-3) hours. $328(15.3 \%)$ patients were admitted to a critical care unit as routine immediately after surgery, with a median critical care stay of $1(1-4)$ days. Of these patients, $161(49.1 \%)$ developed a complication with $14(4.3 \%)$ deaths. 121 patients were admitted to a critical care unit to treat complications, of whom 17 (14\%) died. The median duration of critical care stay for patients admitted to treat a complication was $5(1-10)$ days. The median overall hospital stay was $5(2-10)$ days, increasing to $11(6-18)$ days amongst those patients who developed complications.

\section{Clinical outcomes}

In total, $498(23.2 \%)$ patients developed complications in hospital, and 30 died before hospital discharge (1.4\%). $297(13.9 \%)$ patients developed a single postoperative complication whilst 201 (9.4\%) patients developed two or more complications. Data describing postoperative complications are presented in Table 2. There were 368 infectious complications affecting 254 patients, the most frequent being pneumonia and superficial surgical site infections of varying severity (Table 2). There were 125 complications affecting 97 patients related to technical aspects of surgery, such as postoperative bleeding and anastomotic leak (Table 2). The "All other" category of complications were not specified and included deep vein thrombosis, ileus, pancreatitis etc. Nine patients experiencing complications in this category died, however, all had additionally experienced infectious, cardiovascular, or other complications related to the technical aspects of the procedure. In the initial univariable regression analysis, age (OR 1.03 [1.02-1.04]), American Society of Anesthesiologists (ASA) physical status score III (OR 3.33 [2.32-4.78]) or IV (OR 5.51 [3.07-9.88]), surgery for cancer (OR 2.60 [2.11-3.21]), non-laparoscopic surgery (OR 1.79 [1.45-2.21]), intermediate surgery (OR 1.81 [1.19-2.75]), major surgery (OR 4.34 [2.91-6.48]) and cirrhosis (OR 2.28 [1.05-4.95]) were identified as risk factors for postoperative complications. However during the multivariable logistic regression analysis when adjusted for cofounders, only age, ASA status, surgery for cancer, non-laparoscopic surgery, intermediate and major surgery were identified as independent risk factors for postoperative complications (Table 3). This indicated major upper gastrointestinal surgery to treat cancer as a sub-population at particular risk of poor outcomes (Supplementary Table 1), with twice the rate of complications (224/578 major cancer patients [38.8\%] versus 274/1561 [17.6\%] patients undergoing minor, intermediate, or major non-cancer procedures (Fig. 2). In the major cancer surgery group, $122(21.1 \%)$ patients developed one complication, whilst $102(17.6 \%)$ patients developed two or more complications during their postoperative stay in hospital. Of 2139 patients who underwent upper gastrointestinal surgery, 30 died (1.4\%). Non-survivors were older, had higher ASA scores and underwent major surgery (Supplementary Table 2).

Comparison of high-income and low or middle-income countries:

Using the World Bank classification, eight were classed as low or middle-income countries (Brazil, China, Indonesia, Malaysia, Nigeria, Romania, South Africa, and Uganda), and 19 were classed as high-income countries 
509 hospitals participated in 30 countries $(45,694$ patients)

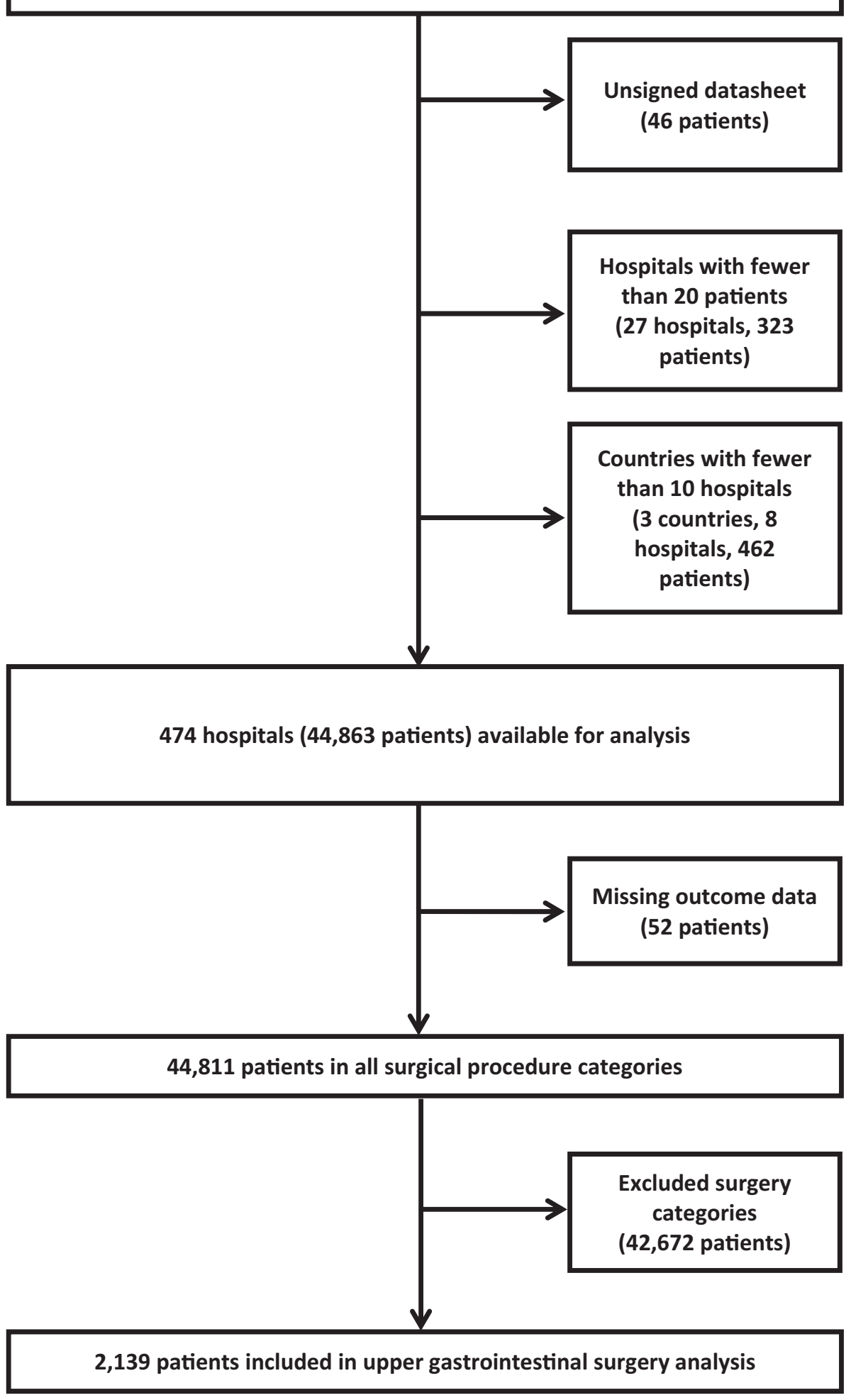

Fig. 1. Patients, hospital and countries excluded from analysis. 
Table 1

Baseline patient characteristics. Data presented as $\mathrm{n}(\%)$ or mean (SD). ASA, American Society of Anesthesiologists physical status score; COPD, chronic obstructive pulmonary disease. We compared patients with or without complications, using Mann-Whitney U and Chi-square tests as appropriate. ${ }^{*}$ signifies $\mathrm{p}<0.05$ compared to patients with complications.

\begin{tabular}{|c|c|c|c|}
\hline & $\begin{array}{l}\text { All patients } \\
(\mathrm{n}=2139)\end{array}$ & $\begin{array}{l}\text { Patients with } \\
\text { complications } \\
(\mathrm{n}=498)\end{array}$ & $\begin{array}{l}\text { Patients without } \\
\text { complications } \\
(\mathrm{n}=1641)\end{array}$ \\
\hline Age & $56(16)$ & $61(15)$ & $55(16)^{*}$ \\
\hline Male & $1034(48.3 \%)$ & $271(54.5 \%)$ & $761(46.3 \%)^{*}$ \\
\hline Female & $1108(51.7 \%)$ & $227(45.6 \%)$ & $881(53.7 \%)^{*}$ \\
\hline Smoker & $397(18.8 \%)$ & $101(20.3 \%)$ & $295(18.3 \%)$ \\
\hline Black ethnicity & $190(9.0 \%)$ & $32(6.5 \%)$ & $158(9.8 \%)^{*}$ \\
\hline \multicolumn{4}{|l|}{ ASA score } \\
\hline I & $337(15.8 \%)$ & $43(8.7 \%)$ & $294(17.9 \%)^{*}$ \\
\hline II & $1104(51.7 \%)$ & $219(44.1 \%)$ & $884(54.0 \%)^{*}$ \\
\hline III & $631(29.5 \%)$ & $206(41.4 \%)$ & $424(25.9 \%)^{*}$ \\
\hline IV & $65(3.0 \%)$ & $29(5.8 \%)$ & $36(2.2 \%)^{*}$ \\
\hline \multicolumn{4}{|l|}{ Severity of surgery } \\
\hline Minor & $297(13.9 \%)$ & $30(6.0 \%)$ & $267(16.3 \%)^{*}$ \\
\hline Intermediate & $857(40.0 \%)$ & $145(29.1 \%)$ & $712(43.4 \%)^{*}$ \\
\hline Major & $985(46.0 \%)$ & $322(64.7 \%)$ & $661(40.3 \%)^{*}$ \\
\hline \multicolumn{4}{|l|}{ Chronic disease } \\
\hline Ischaemic heart disease & $189(8.9 \%)$ & $59(11.8 \%)$ & $130(8.0 \%)^{*}$ \\
\hline Heart failure & $83(3.9 \%)$ & $28(5.6 \%)$ & $55(3.4 \%)^{*}$ \\
\hline Diabetes mellitus & $309(14.5 \%)$ & $79(15.9 \%)$ & $229(14.0 \%)$ \\
\hline Cirrhosis & $27(1.3 \%)$ & $11(2.2 \%)$ & $16(1.0 \%)^{*}$ \\
\hline Surgery for Cancer & $750(35.1 \%)$ & $269(54.0 \%)$ & $479(31.7 \%)^{*}$ \\
\hline Metastatic cancer & $140(6.6 \%)$ & $54(10.8 \%)$ & $86(5.3 \%)^{*}$ \\
\hline Stroke & $73(3.4 \%)$ & $22(4.4 \%)$ & $51(3.1 \%)$ \\
\hline COPD/Asthma & $240(11.3 \%)$ & $62(12.4 \%)$ & $178(10.9 \%)$ \\
\hline Other chronic disease & $926(43.4 \%)$ & $259(52.0 \%)$ & $630(38.6 \%)^{*}$ \\
\hline \multicolumn{4}{|l|}{ Blood test results } \\
\hline Haemoglobin (g/dL) & $12.7(2.1)$ & $12.3(2.2)$ & $12.9(2.1)^{*}$ \\
\hline Creatinine $(\mu \mathrm{mol} / \mathrm{L})$ & $79(53)$ & $84(54)$ & $77(52)^{*}$ \\
\hline Sodium $(\mathrm{mmol} / \mathrm{L})$ & $139(6)$ & $139(8)$ & $140(5)$ \\
\hline Leucocytes $\left(\times 10^{-9} / \mathrm{mm}^{3}\right)$ & $7.7(4.6)$ & $8.4(7.6)$ & $7.4(2.9)$ \\
\hline Laparoscopic technique & $936(43.7 \%)$ & $165(33.1 \%)$ & $770(47.0 \%)^{*}$ \\
\hline
\end{tabular}

(Australia, Austria, Belgium, Canada, Denmark, France, Germany, Greece, Hong Kong, Italy, Netherlands, New Zealand, Portugal, Russia, Spain, Sweden, Switzerland, United Kingdom, and the United States of America) [24]. Patient outcomes for major cancer surgery in high-income countries were similar to the overall international subgroup with 326/1270 patients (25.7\%) developing complications with six deaths $(2.3 \%)$. In this post-hoc analysis, complication rates were lower in the low or middleincome countries 172/869 (19.8\%) $\mathrm{p}<0.001$. When explored this we found that although age was similar in both the high and low or middle-income countries 57 (44-68) vs 58 (46-66) years, ASA distribution significantly differed with more ASA 2, 3 and 4 patients being operated in the high income countries (Supplementary Fig. 1). Patients in high-income countries underwent fewer minor procedures (Supplementary Fig. 2). There were no significant differences between high or low and middle- income countries in terms of risk of complications in the univariable analysis.

\section{Discussion}

We report data from an international prospective cohort study describing detailed postoperative outcomes for a population of more than 2000 patients undergoing elective upper gastrointestinal surgery in 27 countries worldwide. The principal findings were that one in four patients experienced a complication before hospital discharge, compared to one in six of the overall surgical population in the parent study [19]. Surgery involving the upper gastrointestinal tract was associated with higher risk of complications compared to the reference category of orthopaedic surgery in the complete ISOS dataset [19]. According to our results, complications in the upper gastrointestinal surgery group were associated with a two-fold increase in hospital stay, and one in fifteen patients who developed a complication died before hospital discharge. Patients undergoing major cancer surgery are at particular risk, with twice the postoperative complication rate of other patients undergoing upper gastrointestinal surgery. In the univariable analysis, risk of complication was similar when high-income countries were compared to low and middle-income countries. Our results suggest that the greater crude complication rates in highincome countries largely relate to differences in casemix. This finding suggests that measures to reduce complication rates remain important in all countries, regardless of income status.

The complication rates observed in this analysis are lower than those reported in recently studies from Sweden, Japan, Australia and the UK [16,25-27]. The Australian, Japanese and UK studies all reported complications during hospital stay, similar to our methods. Unlike our contemporary snapshot of practice, these studies collected information on patients over several years [25-27]. The ongoing change and improvement in clinical practice over the last decade might partly account for the lower observed complication rates in our series [28] Infectious complications such as surgical site infections and pneumonia remain commonplace, and are associated with prolonged hospital stays. In previous studies, pneumonia rates as high as $22.5 \%$ were reported following oesophagectomy, whereas in our series the rate was only $4.0 \%$, even in the major cancer surgery sub-group [16,25-27]. Similarly, technical complications of surgery were less frequent in this dataset, although this may relate to differences in casemix and improvements in surgical technique and perioperative care compared to the standards observed in previous studies in this international patient sample [16,25-27].

Mortality rates were lower than expected given the observed complication rates. It is possible that this relates to improvements in the care of patients who develop complications, although this may also be affected by the duration of critical care stay for patients who develop life 
Table 2

Complication rates for patients undergoing elective upper gastrointestinal surgery using the Clavien-Dindo classification (I to V). Percentages expressed as a proportion of all patients included in the analysis $(\mathrm{n}=2139)$. ARDS, acute respiratory distress syndrome.

$\begin{array}{lllll}\text { Severity class I } & \text { Severity class II } & \text { Severity class III } & \text { Severity class IV } & \text { Severity class V }\end{array}$

Cumulative

complication

rate

\begin{tabular}{|c|c|c|c|c|c|c|}
\hline \multicolumn{7}{|l|}{ Infection } \\
\hline Pneumonia N (\%) & $31(1.4 \%)$ & $46(2.1 \%)$ & $0(0 \%)$ & $21(1.0 \%)$ & $10(0.5 \%)$ & $108(5.0 \%)$ \\
\hline Superficial surgical site N (\%) & $42(2.0 \%)$ & $28(1.3 \%)$ & $5(0.2 \%)$ & $3(0.1 \%)$ & $1(0.1 \%)$ & $79(3.7 \%)$ \\
\hline Body cavity $\mathrm{N}(\%)$ & $24(1.2 \%)$ & $19(0.9 \%)$ & $0(0 \%)$ & $19(0.9 \%)$ & $2(0.1 \%)$ & $64(3.0 \%)$ \\
\hline Deep surgical site N (\%) & $12(0.6 \%)$ & $25(1.2 \%)$ & $0(0 \%)$ & $12(0.6 \%)$ & $4(0.2 \%)$ & $53(2.5 \%)$ \\
\hline Bloodstream N (\%) & $11(0.5 \%)$ & $14(0.7 \%)$ & $1(0.1 \%)$ & $9(0.4 \%)$ & $6(0.3 \%)$ & $41(1.9 \%)$ \\
\hline Urinary tract $\mathrm{N}(\%)$ & $12(0.6 \%)$ & $14(0.7 \%)$ & $0(0 \%)$ & $1(0.1 \%)$ & $4(0.2 \%)$ & $31(1.4 \%)$ \\
\hline \multicolumn{7}{|l|}{ Cardiovascular } \\
\hline Arrhythmia N (\%) & $35(1.6 \%)$ & $36(1.7 \%)$ & $3(0.1 \%)$ & $8(0.4 \%)$ & $6(0.3 \%)$ & $88(4.1 \%)$ \\
\hline Pulmonary oedema N (\%) & $14(0.7 \%)$ & $4(0.2 \%)$ & $0(0 \%)$ & $3(0.1 \%)$ & $1(0.1 \%)$ & $22(1.0 \%)$ \\
\hline Cardiac arrest $\mathrm{N}(\%)$ & - & - & - & $5(0.2 \%)$ & $9(0.5 \%)$ & $14(0.7 \%)$ \\
\hline Myocardial infarction N (\%) & $1(0.1 \%)$ & $2(0.1 \%)$ & $0(0 \%)$ & $3(0.1 \%)$ & $2(0.1 \%)$ & $8(0.4 \%)$ \\
\hline Pulmonary embolism N (\%) & $1(0.1 \%)$ & $3(0.1 \%)$ & $0(0 \%)$ & $2(0.1 \%)$ & $0(0 \%)$ & $6(0.3 \%)$ \\
\hline Stroke N $(\%)$ & $1(0.1 \%)$ & $0(0 \%)$ & $0(0 \%)$ & $2(0.1 \%)$ & $3(0.2 \%)$ & $6(0.3 \%)$ \\
\hline \multicolumn{7}{|l|}{ Other complications } \\
\hline Post-operative bleeding N (\%) & - & $56(2.6 \%)$ & $0(0 \%)$ & $11(0.5 \%)$ & $14(0.7 \%)$ & $81(3.8 \%)$ \\
\hline Acute kidney injury $\mathrm{N}(\%)$ & $24(1.1 \%)$ & $22(1.0 \%)$ & $0(0 \%)$ & 10 & $12(0.6 \%)$ & $68(3.2 \%)$ \\
\hline Anastomotic leakage N (\%) & $12(0.6 \%)$ & $12(0.6 \%)$ & $5(0.2 \%)$ & $20(0.9 \%)$ & $6(0.3 \%)$ & $55(2.6 \%)$ \\
\hline Gastro-intestinal bleeding $\mathrm{N}(\%)$ & $23(1.1 \%)$ & $11(0.5 \%)$ & $0(0 \%)$ & $1(0.1 \%)$ & $4(0.2 \%)$ & $39(1.8 \%)$ \\
\hline ARDS N $(\%)$ & $8(0.4 \%)$ & $8(0.4 \%)$ & $0(0 \%)$ & $3(0.1 \%)$ & $5(0.2 \%)$ & $24(1.1 \%)$ \\
\hline All others $\mathrm{N}(\%)$ & $84(3.9 \%)$ & $80(3.7 \%)$ & $7(0.3 \%)$ & $11(0.5 \%)$ & $9(0.4 \%)$ & $191(8.9 \%)$ \\
\hline Total N (\%) & $434(20.3 \%)$ & $380(17.8 \%)$ & $21(1.0 \%)$ & $139(6.5 \%)$ & $30(1.4 \%)$ & \\
\hline
\end{tabular}

threatening complications after major elective surgery, which may now routinely exceed 30 days before treatment is withdrawn for reasons of futility. In this context, 30-day mortality may not truly reflect the seriousness of eventual patient outcomes. The risk factors for postoperative complications identified in the ISOS study are well recognised. Age has been shown to be independently associated with higher post-operative morbidity and mortality after major upper gastrointestinal procedures [29-31], although age

\section{Table 3}

Results of the multivariate logistic regression model for postoperative complications following upper gastrointestinal surgery. ASA, American Society of Anesthesiologists physical status score. Data presented as adjusted odds ratios presented with $95 \%$ confidence intervals. 148 patients were omitted from the multivariable model due to missing data on one or more covariates. Age: no reference. Odds ratio for age is indexed to years of difference in age, so that in the multivariable model odds ratio for a tenyear increase in age is $1.021=1.18$. ASA was treated as a single ordered categorical variable with ASA I as the reference to all other categories $(\mathrm{OR}=1.0)$. Cirrhosis - reference: no cirrhosis. Intermediate surgery reference: minor surgery. Major surgery - reference: minor surgery. Cancer surgery - reference: non-cancer surgery. Open Surgery - reference: laparoscopic surgery.

\begin{tabular}{lll}
\hline & Multivariable model OR $(95 \% \mathrm{CI})$ & $\mathrm{p}$-value \\
\hline Age & $1.02(1.01-1.03)$ & $<0.001$ \\
ASA II & $1.13(0.78-1.66)$ & 0.540 \\
ASA III & $2.12(1.44-3.16)$ & $<0.001$ \\
ASA IV & $3.23(1.72-6.09$ & $<0.001$ \\
Cirrhosis & $2.12(0.91-4.78)$ & 0.072 \\
Intermediate surgery & $1.75(1.12-2.81)$ & 0.016 \\
Major surgery & $2.65(1.72-4.23)$ & $<0.001$ \\
Cancer surgery & $1.63(1.27-2.11)$ & $<0.001$ \\
Open surgery & $1.40(1.10-1.78)$ & 0.006 \\
\hline
\end{tabular}

alone should not be viewed as a reason to deny patients a definitive surgical treatment. A recent Australian study did not demonstrate any correlation between age and long-term survival, even though postoperative complications were more frequent amongst elderly patients [31]. The findings from our larger international study are consistent with this previous work, confirming the high incidence of complications early after upper gastrointestinal surgery amongst elderly patients. ASA score has been highlighted as a strong predictor of postoperative complications [32]. It is interesting to note that a relatively large proportion of patients undergoing upper gastrointestinal surgery were classed as ASA III or IV, in both cancer and non-cancer cancer groups, with a corresponding increase in the frequency of complications. Similar findings have recently been reported in the UK, with one third of patients undergoing oesophagectomy falling into ASA III and IV categories [33] Recent recommendations for the treatment of upper gastrointestinal cancer recommend careful patient selection based on physiological reserve and pre-existing comorbid disease $[34,35]$. One in six patients in this cohort were admitted to a critical care unit immediately after surgery, half of whom experienced postoperative complications. Although significant progress has been made in the development of perioperative pathways to improve patient outcomes, it remains uncertain what the most appropriate level of postoperative care should be for this high-risk patient group. This is highlighted in the findings of a recent analysis of a large US dataset, which did not identify any benefit of routine critical care admission immediately after major upper gastrointestinal cancer surgery [36]. The 


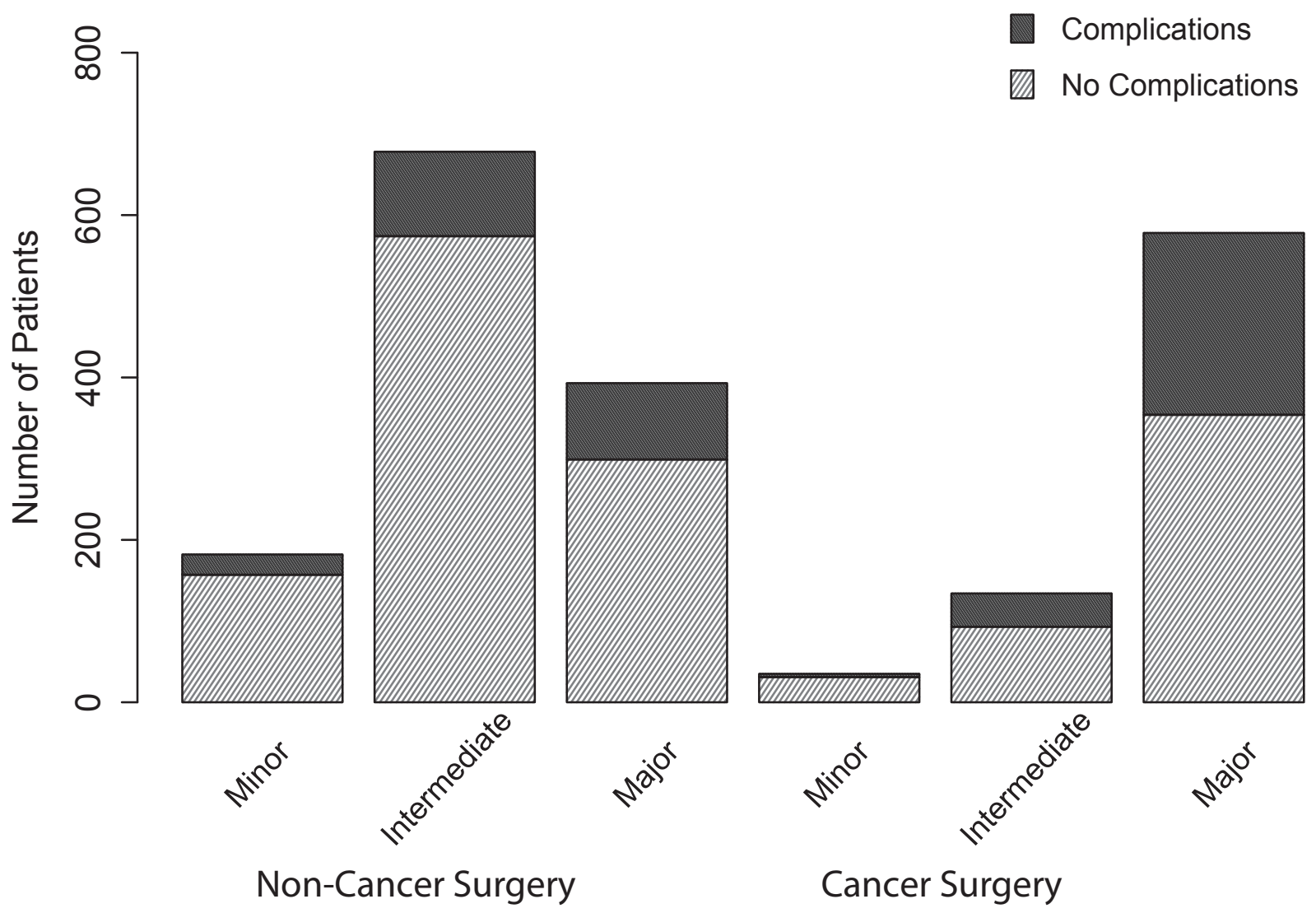

Fig. 2. Distribution of postoperative complications in major cancer surgery $(\mathrm{n}=578)$ and other upper gastrointestinal procedures $(\mathrm{n}=1561)$.

secondary analysis of the ISOS dataset also failed to signal any mortality benefit of routine critical care admission following high-risk elective surgery [37].

The strengths of this study have been discussed in detail in our previous publication [19]. We used a very simple data set consisting primarily of categorical variables to aid data collection and minimising empty data fields. Patient-level variables were selected on the basis that they were objective, and routinely available to local investigators. We carefully defined surgical procedure categories to identify patients undergoing major upper gastrointestinal surgery by either the abdominal or thoracic route. We also asked investigators to confirm whether the indication for surgery was cancer. The study also has a number of weaknesses. The ISOS project was prospectively designed to allow us to clearly identify patients undergoing upper gastrointestinal surgery, but its' main objective was to evaluate all elective in-patient surgery. Baseline data were not specific to the upper gastrointestinal surgical procedure category, and our multivariable model may not fully account for high mortality rates in hospitals specialising in more complex surgery due to the low number of patients recruited in each centre. It is possible, that given the pragmatic nature of ISOS study looking at only complications during the hospital stay, we missed some of the later events, possibly resulting in an under-estimate of the incidence of postoperative complications. Also, due to the pragmatic nature of the study, external verification of the imputed data was not possible, potentially resulting in misreporting of complications. However, the similar studies from different countries also limited their data collection period to in-hospital stay or 30 days postoperatively and suffered from lack of external data verification $[16,25-28]$.

\section{Conclusions}

The findings of this international cohort study indicate that a large number of patients develop complications after elective in-patient upper gastrointestinal surgery. Patients undergoing major cancer surgery were at particular risk with complication rates approaching one in two patients. To improve patient outcomes, the concept of perioperative medicine is being adopted more widely to ensure safe and effective patient care throughout the perioperative care pathway $[38,39]$. International datasets help to set out the baseline for further quality improvement initiatives and can be used for perioperative decision-making and informed consent during upper gastrointestinal surgery.

\section{Conflict of interest statement}

RP has given lectures and/or performed consultancy work for Nestle Health Sciences, Medtronic, Edwards Lifesciences, GlaxoSmithkline and BBraun, and has received 
research funding from Nestle Health Sciences, BBraun, and Edwards Lifesciences, and is a member of the Associate editorial board of the British Journal of Anaesthesia. All other authors declare they have no conflicts of interest.

\section{Contributors}

RP conceived the analysis and designed this with TS and JP. Patient recruitment and data collection were performed by the members of the International Surgical Outcomes Study group (see Appendix). TS and JP performed the data analysis. The manuscript was drafted by TS and RP, and then revised following critical review by all co-authors.

\section{Data sharing}

The authors are happy to consider data sharing requests from bona fide researchers. Participant consent was not obtained but the presented data are anonymised and risk of identification is low. Enquiries should be addressed to the chief investigator at: admin@isos.org.uk.

\section{Acknowledgements}

This was an investigator-initiated study funded by Nestle Health Sciences through an unrestricted research grant, and by a National Institute for Health Research (UK) Professorship held by RP. The study was sponsored by Queen Mary University of London. The study funders and sponsor had no involvement in the study design, in the collection, analysis and interpretation of the data, in the writing of the manuscript; and in the decision to submit the manuscript for publication. The International Surgical Outcomes Study group investigators (collaborators listed in the Supplementary Appendix) were entirely responsible for study design, conduct and data analysis. The authors had full data access and were solely responsible for data interpretation, drafting and critical revision of the manuscript, and the decision to submit for publication.

\section{Appendix A. Supplementary data}

Supplementary data related to this article can be found at http://dx.doi.org/10.1016/j.ejso.2017.08.002.

\section{References}

[1] Weiser TG, Regenbogen SE, Thompson KD, Haynes AB, Lipsitz SR, Berry WR, et al. An estimation of the global volume of surgery: a modelling strategy based on available data. Lancet 2008;372: $139-44$.

[2] Weiser TG, Haynes AB, Molina G, Lipsitz SR, Esquivel MM, UribeLeitz T, et al. Estimate of the global volume of surgery in 2012: an assessment supporting improved health outcomes. Lancet 2015;385: S11.
[3] Pearse RM, Moreno RP, Bauer P, Pelosi P, Metnitz P, Spies C, et al. Mortality after surgery in Europe: a 7 day cohort study. Lancet 2012; 380:1059-65.

[4] Findlay G, Goodwin A, Protopapa K, Smith NE, Mason M. Knowing the Risk; A review of the peri-operative care of surgical patients. Natl Confid Enq into Patient Outcome Death 2011:1-98.

[5] Jhanji S, Thomas B, Ely A, Watson D, Hinds CJ, Pearse RM. Mortality and utilisation of critical care resources amongst high-risk surgical patients in a large NHS trust. Anaesthesia 2008;63:695-700.

[6] Pearse RM, Harrison DA, James P, Watson D, Hinds C, Rhodes A, et al. Identification and characterisation of the high-risk surgical population in the United Kingdom. Crit Care 2006;10:R81.

[7] Glance LG, Lustik SJ, Hannan EL, Osler TM, Mukamel DB, Qian F, et al. The surgical mortality probability model: derivation and validation of a simple risk prediction rule for noncardiac surgery. Ann Surg 2012;255:696-702.

[8] Jencks SF, Williams MV, Coleman EA. Rehospitalizations among patients in the Medicare fee-for-service program. N Engl J Med 2009;360:1418-28.

[9] Noordzij PG, Poldermans D, Schouten O, Bax JJ, Schreiner FAG, Boersma E. Postoperative mortality in The Netherlands: a population-based analysis of surgery-specific risk in adults. Anesthesiology 2010;112:1105-15.

[10] Yu PC, Calderaro D, Gualandro DM, Marques AC, Pastana AF, Prandini JC, et al. Non-cardiac surgery in developing countries: epidemiological aspects and economical opportunities-the case of Brazil. PLoS One 2010;5(5), e10607.

[11] Scally CP, Thumma JR, Birkmeyer JD, Dimick JB. Impact of surgical quality improvement on payments in medicare patients. Ann Surg 2014:262:249-52.

[12] Sadique Z, Harrison DA, Grieve R, Rowan KM, Pearse RM, OPTIMISE study group. Cost-effectiveness of a cardiac output-guided haemodynamic therapy algorithm in high-risk patients undergoing major gastrointestinal surgery. Perioper Med 2015;4:13.

[13] Head J, Ferrie JE, Alexanderson K, Westerlund H, Vahtera J, Kivimäki M, et al. Diagnosis-specific sickness absence as a predictor of mortality: the Whitehall II prospective cohort study. BMJ 2008; 337. a1469.

[14] Pearse RM, Holt PJ, Grocott MP. Managing perioperative risk in patients undergoing elective non-cardiac surgery. BMJ 2011;343. d5759.

[15] Siegel R, Ma J, Zou Z, Jemal A. Cancer statistics, 2014. CA Cancer J Clin 2014;64:9-29.

[16] Chadwick G, Taylor A, Groene O, Cromwell D, Hardwick R, Riley S, et al. The national oesophago-gastric cancer audit. Audit Care Receiv People Oesophago Gastric Cancer Engl Wales 2014: $1-61$.

[17] Smith RC, Creighton N, Lord RV, Merrett ND, Keogh GW, Liauw WS, et al. Survival, mortality and morbidity outcomes after oesophagogastric cancer surgery in New South Wales, 2001-2008. Med J Aust 2014;200:408-13.

[18] Markar SR, Schmidt H, Kunz S, Bodnar A, Hubka M, Low DE. Evolution of standardized clinical pathways: refining multidisciplinary care and process to improve outcomes of the surgical treatment of esophageal cancer. J Gastrointest Surg 2014;18:1238-46.

[19] ISOS group investigators. Global patient outcomes after elective surgery: prospective cohort study in 27 low-, middle- and high-income countries. Br J Anaesth 2016;117:601-9.

[20] Elm von E, Altman DG, Egger M, Pocock SJ, Gøtzsche PC, Vandenbroucke JP, et al. The Strengthening the Reporting of Observational Studies in Epidemiology (STROBE) statement: guidelines for reporting observational studies. PLOS Med 2007;4:e296.

[21] Jammer I, Wickboldt N, Sander M, Smith A, Schultz MJ, Pelosi P, et al. Standards for definitions and use of outcome measures for clinical effectiveness research in perioperative medicine: European Perioperative Clinical Outcome (EPCO) definitions: a statement from the ESA-ESICM joint taskforce on perioperative outcome measures. Eur J Anaesthesiol 2015;32:88-105. 
[22] Dindo D, Demartines N, Clavien PA. Classification of surgical complications: a new proposal with evaluation in a cohort of 6336 patients and results of a survey. Ann Surg 2004;240:205-13.

[23] Akaike H. Akaike's information criterion. In: International encyclopedia of statistical science. Berlin: Springer; 2011. 25-5.

[24] World Bank classification of national income. 2016. http://www. worldbank.org/en/country. [Accessed 3 November 2016].

[25] Booka E, Takeuchi H, Nishi T, Matsuda S, Kaburagi T, Fukuda K, et al. The impact of postoperative complications on survivals after esophagectomy for esophageal cancer. Med (Baltim) 2015;94, e1369.

[26] Hii MW, Smithers BM, Gotley DC, Thomas JM, Thomson I, Martin I, et al. Impact of postoperative morbidity on long-term survival after oesophagectomy. Br J Surg 2013;100:95-104.

[27] Rutegård M, Lagergren P, Rouvelas I, Mason R, Lagergren J. Surgical complications and long-term survival after esophagectomy for cancer in a nationwide Swedish cohort study. Eur J Surg Oncol 2012;38:555-61.

[28] Markar SR, Karthikesalingam A, Low DE. Enhanced recovery pathways lead to an improvement in postoperative outcomes following esophagectomy: systematic review and pooled analysis. Dis Esophagus 2015;28:468-75.

[29] Abunasra H, Lewis S, Beggs L, Duffy J, Beggs D, Morgan E. Predictors of operative death after oesophagectomy for carcinoma. Br J Surg 2005;92:1029-33.

[30] McLoughlin JM, Lewis JM, Meredith KL. The impact of age on morbidity and mortality following esophagectomy for esophageal cancer. Cancer Control 2013;20:144-50.

[31] O’Grady G, Hameed AM, Pang TC, Johnston E, Lam VT, Richardson AJ, et al. Patient selection for oesophagectomy: impact of age and comorbidities on outcome. World J Surg 2015;39:1994-9.
[32] Sauvanet A, Mariette C, Thomas P, Lozac'h P, Segol P, Tiret E, et al. Mortality and morbidity after resection for adenocarcinoma of the gastroesophageal junction: predictive factors. J Am Coll Surg 2005;201:253-62.

[33] Fischer C, Lingsma H, Hardwick R, Cromwell DA, Steyerberg E, Groene O. Risk adjustment models for short-term outcomes after surgical resection for oesophagogastric cancer. Br J Surg 2016;103: 105-16.

[34] Alldinger I, Sisic L, Hochreiter M, Weichert W, Blank S, Burian M, et al. Outcome, complications, and mortality of an intrathoracic anastomosis in esophageal cancer in patients without a preoperative selection with a risk score. Langenbecks Arch Surg 2015; 400:9-18.

[35] Atkins BZ, Shah AS, Hutcheson KA, Mangum JH, Pappas TN, Harpole DH, et al. Reducing hospital morbidity and mortality following esophagectomy. Ann Thorac Surg 2004;78:1170-6.

[36] Wunsch H, Gershengorn HB, Cooke CR, Guerra C, Angus DC, Rowe JW, et al. Use of intensive care services for medicare beneficiaries undergoing major surgical procedures. Anesthesiology 2016; 124:899-907.

[37] Kahan BC, Koulenti D, Arvaniti K, Beavis V, Campbell D, Chan M, et al. Relationship between critical care provision and mortality following elective surgery: prospective analysis of data from 27 countries. Intensive Care Med 2017;43:971-9.

[38] Greco M, Capretti G, Beretta L, Gemma M, Pecorelli N, Braga M. Enhanced recovery program in colorectal surgery: a meta-analysis of randomized controlled trials. World J Surg 2014;38:1531-41.

[39] King AB, Alvis BD, McEvoy MD. Enhanced recovery after surgery, perioperative medicine, and the perioperative surgical home: current state and future implications for education and training. Curr Opin Anaesthesiol 2016;29:727-32. 